\title{
COMPARISON OF HEMATO-BIOCHEMICAL PARAMETERS BETWEEN APPARENTLY HEALTHY AND BOVINE TUBERCULOSIS AFFECTED CATTLE IN CHITTAGONG, BANGLADESH
}

\author{
M. B. Hossain ${ }^{1 *}$, M. M. Khan ${ }^{2}$, M. A. Rumi ${ }^{3}$, M. Ahammed ${ }^{4}$ and M. S. Bari ${ }^{5}$
}

${ }^{1}$ Department of Physiology, Biochemistry and Pharmacology, ${ }^{3}$ Department of Medicine and Surgery, ${ }^{5}$ Department of Dairy and Poultry Science, Faculty of Veterinary Medicine, Chittagong Veterinary and Animal Sciences University, Khulshi, Chittagong-4225, Bangladesh; ${ }^{2}$ Directorate of Livestock Services, Dhaka, Bangladesh; ${ }^{4}$ Department of Pathology, Faculty of Veterinary Science, Bangladesh Agricultural University, Mymensingh-2202, Bangladesh

\begin{abstract}
The cross-sectional study was carried out to compare the hematological and serum biochemical profiles between bovine tuberculosis (bTB) affected and apparently healthy cattle during the period from March 2014 to October 2016. A total of 189 blood samples were collected from $93 \mathrm{bTB}$ affected and 96 apparently healthy cattle of 3 Upazilas of Chittagong. The bovine tuberculosis (bTB) was diagnosed primarily by Caudal Fold Tuberculin Tests (CFTT) and confirmed by the Comparative Intradermal Tuberculin Test (CITT). The whole blood was analyzed for hematology, and serum samples were used for biochemical analysis. The study revealed that, the values for TEC, Hb and PCV were higher in infected cohort (based on CFTT) in compare to their counterpart control group. Among these three parameters only PCV values were statistically significant $(\mathrm{P} \leq 0.05)$. Only basophil percentage was significantly $(\mathrm{P} \leq 0.05)$ higher in infected cohort. The values of total protein, albumin, creatinine and SGOT were insignificantly lower and the values of calcium \& phosphorus were also insignificantly higher in bTB affected cattle than control group of cattle.
\end{abstract}

Key words: Biochemistry, bovine tuberculosis, cattle, hematology, serum profile

\section{INTRODUCTION}

In the developing countries, Tuberculosis (TB) is considered one of the common illnesses which affect peoples of all classes of the society and zoonotic TB (animal origin Human TB) is an important public health concern (Tsegaye et al., 2010). Pasteurization of milk is not well practiced in most developing countries and 10-15\% human TB is animal origin (Mycobacterium bovis) (Ashford et al., 2001). In Bangladesh, TB remains a major public health problem and ranks fourth in the world for both prevalence and mortalities. In 2014, due to TB about 81,000 Bangladeshi died and 1, 96,797 were new cases though case notification rate is very low (53\%) (USAID TB CARE II Project, Bangladesh). Due to higher population density, the demand of milk is more in Bangladesh and to fulfill these excessive demand intensive dairy farms with high yielding crossbreeds are increasing especially in urban and periurban areas which are more susceptible to bTB (Haque et al., 2016). One billion people of the world are infected with tubercle bacillus and decreased immunity increases in case of the development of active TB. Malnutrition, diabetes, prolonged use of corticosteroid drugs, gastrectomy, and immune suppressive drugs are the probable risk factors for developing active TB (Uddin et al., 2014; Priya et al., 2015).

In active tuberculosis, the causative organisms produce tubercle mainly in lungs and lymph nodes and also affect hematobiochemical parameters like other infectious diseases (Javed et al., 2010). Blood is a representation of body tissues which is used to assess general health, diagnosis of disease and to evaluate the progress of certain disease status (Jain, 1986; Sharma and Singh, 2000). On the other hand, biochemical analyses of blood serum are very useful to get insight into the metabolic and health status of animals. Thus, hematobiochemical parameters could be good indices for diagnosis of diseases in animals (Bari et al., 2018). During diagnostic procedure, it is very useful to compare the values obtained from ill animals with normal values in healthy animal (Ježek et al., 2006). Variation in blood parameters also observed in animals due to several environmental and physiological factors (Shaikat et al., 2013). In Bangladesh, Samad and Rahman (1986) found decreased level of Total Erythrocyte Count (TEC), Hemoglobin concentration and Neutrophil percentage and increased level of Erythrocyte Sedimentation Rate (ESR), Total Leukocyte Count (TLC) and Lymphocyte percentage. In Pakistan, Javed et al., (2006 and 2010) conducted two studies on hematological and serum protein levels on tuberculin reactor and non-reactor animals and found some significant alterations. Hematological and serum protein levels were also evaluated on tuberculin reactor and nonreactor dairy cattle in Iraq and also found some significant alterations (Salman et al., 2013). In India, Shettar et al., (2011) compared both hematological and biochemical parameters from an organized dairy farm and observed significant variations of some parameters between reactor and non- reactor animals. On the basis of above discussion, the study was conducted with a large sample size to give an idea about the hematobiochemical parameters between tuberculin reactor \& non-reactor dairy cattle in Chittagong, Bangladesh which might be contributing in the uncomplicated prompt diagnosis of bTB with greater efficacy.

*Corresponding e-mail address: mbhossaincvasu@yahoo.com 


\section{Hossain and others}

\section{MATERIALS AND METHODS}

\section{Study design}

The study was conducted in 3 selected Upazila namely Double Mooring, Patiya and Raozan of Chittagong district of Bangladesh. The Upazila were selected purposively based on the fact that dairy farming is concentrated in these areas. The cross sectional study was carried out during the period from March 2014 to October 2016. All the dairy cattle of the selected Upazila (Double Mooring, Patiya and Raozan) of Chittagong district were the study population. The selected 37 farms from three studied areas, CFTT was done on 846 animals and 119 animals of 27 farms shown positive results. To compare the values of different hematological parameters between CFTT positive and negative reactors, total 119 animals were targeted to collect blood. Due to farmer's non-cooperation, 93 whole blood samples were collected from CFTT positive animals. Almost equal numbers of blood samples from respected farms were collected as control groups. The more definite follow-up test CITT was done on CFTT positive animals and 49 cattle were found CITT positive reactors. Within these 49 cattle, 44 analyzed results were found. These CITT positive 44 analyzed values were compared with CFTT negative 96 analyzed values. More definite follow-up test, CITT was done only on primary screening CFTT responders. According to OIE recommended cut-off value (4mm and above) the no. of CITT positive animals \& farms were 49 and 13 respectively. Within these 49 CITT positive animals, 45 good quality serum samples were got for biochemical analysis. To compare the effect of $M$. bovis infection on different biochemical parameters, 55 CITT negative cattle from respective farms were selected and these samples were used as controls. Different biochemical parameters Total Protein (TP), Calcium, Phosphorus, Creatinine \& SGOT were analyzed by automatic biochemical analyzer (Humalyzer-3000, USA) and compared with the values between CITT positive and negative reactors.

\section{Statistical analysis}

All of the field and laboratory data were imported to the Microsoft Office Excel-2007 and then transferred to the software STATA/IC-13 for statistical analysis. Descriptive statistics were done followed by T-test by using STATA13 statistical software to determine the associations between the risk factors and to view as significant at a $\mathrm{P}$ value of $\leq 0.05$.

\section{RESULTS}

Within 846 CFTT performed animals, 116 animals showed CFTT positive. Ninety-three (93) blood samples were collected from CFTT positive animals and remaining were missed due to farmers' non-cooperation, selling of the animals, death of the animals etc. Almost equal numbers of blood samples from CFTT negative/ control animals were collected from respected farms. We did complete blood test (TEC, TLC, PCV, ESR, Hb estimation, DLC Lymphocyte, Neutrophil, Eosinophil, Basophil \& Monocyte percentage) to determine the variations influenced by the Mycobacterium bovis infection.

Table 1. Comparison of hematological parameters between tuberculin reactor and non-reactor cattle with Mycobacterium bovis infection (performed only by CFTT)

\begin{tabular}{|c|c|c|c|c|}
\hline Variable & Category & Mean \pm SEM & $95 \% \mathrm{CI}$ & P-value \\
\hline \multirow{2}{*}{ TEC $\left(10^{6} / \mu 1\right)$} & Positive(n=93) & $03.74 \pm 0.11$ & $03.53-03.95$ & 0.60 \\
\hline & Negative $(n=96)$ & $03.65 \pm 0.13$ & $03.40-03.90$ & \\
\hline \multirow[t]{2}{*}{$\operatorname{TLC}\left(10^{3} / \mu \mathrm{l}\right)$} & Positive(n=93) & $06.78 \pm 0.23$ & $06.31-07.24$ & 0.78 \\
\hline & Negative $(n=96)$ & $06.69 \pm 0.20$ & 06.29-07.09 & \\
\hline \multirow{2}{*}{$\operatorname{PCV}(\%)$} & Positive(n=93) & $29.45 \pm 0.41$ & $28.64-30.27$ & 0.01 \\
\hline & Negative $(n=96)$ & $28.00 \pm 0.40$ & $27.20-28.80$ & \\
\hline \multirow[t]{2}{*}{$\operatorname{ESR}\left(\mathrm{mm}\right.$ in $\left.1^{\mathrm{st}} \mathrm{hr}.\right)$} & Positive(n=93) & $0.68 \pm 0.06$ & $0.56-0.80$ & 0.67 \\
\hline & $\operatorname{Negative}(n=96)$ & $0.65 \pm 0.06$ & $0.52-0.77$ & \\
\hline \multirow[t]{2}{*}{$\mathrm{Hb}(\mathrm{g} / \mathrm{dl})$} & Positive(n=93) & $08.92 \pm 0.11$ & 08.70-09.14 & 0.72 \\
\hline & Negative $(n=96)$ & $08.87 \pm 0.11$ & 08.66-09.08 & \\
\hline \multirow[t]{2}{*}{ Lymphocyte (\%) } & Positive(n=93) & $57.11 \pm 0.95$ & $55.23-58.99$ & 0.21 \\
\hline & Negative $(n=94)$ & $58.79 \pm 0.95$ & $56.90-60.68$ & \\
\hline \multirow[t]{2}{*}{ Neutrophil (\%) } & Positive(n=93) & $33.73 \pm 0.90$ & $31.94-35.52$ & 0.31 \\
\hline & Negative $(n=94)$ & $32.43 \pm 0.91$ & $30.62-34.23$ & \\
\hline \multirow[t]{2}{*}{ Eosinophil (\%) } & Positive(n=93) & $04.74 \pm 0.27$ & $04.21-05.28$ & 0.52 \\
\hline & Negative $(n=94)$ & $04.52 \pm 0.21$ & $04.11-04.93$ & \\
\hline \multirow[t]{2}{*}{ Basophil (\%) } & Positive(n=93) & $0.30 \pm 0.05$ & $0.20-0.40$ & 0.04 \\
\hline & Negative $(n=94)$ & $0.17 \pm 0.04$ & $0.09-0.25$ & \\
\hline \multirow[t]{2}{*}{ Monocyte (\%) } & Positive(n=93) & $04.26 \pm 0.22$ & $03.82-04.69$ & 0.90 \\
\hline & Negative $(n=94)$ & $04.30 \pm 0.24$ & $03.82-04.77$ & \\
\hline
\end{tabular}

Table 1 shows the values for TEC, Hb and PCV were higher in infected group in compare to their counterpart control group. Among these three parameters, only PCV values were statistically significant $(\mathrm{P} \leq 0.05)$ and other two indices ( $\mathrm{Hb} \&$ TEC) were statistically insignificant. The Leukocyte concentrations per cubic millimeter of blood were determined for both infected and control group. For this parameter, we did not find any significant variations between 
two groups, though the infected group showed slight increase values than controls $(\mathrm{P}=0.78)$. Through Differential Leukocyte Count (DLC), the percentages of different Leukocyte family members (Lymphocyte, Neutrophil,

Eosinophil, Basophil \& Monocyte) were determined for both groups of animals. For all five members of the Leukocyte group, only Basophil percentage was significantly $(\mathrm{P} \leq 0.05)$ higher in the infected cohort.

Table 2. Comparison of hematological parameters between tuberculin reactor and non-reactor cattle with Mycobacterium bovis infection.

\begin{tabular}{|c|c|c|c|c|}
\hline Variable & Category & Mean \pm SEM & $95 \% \mathrm{CI}$ & P-value \\
\hline \multirow[t]{2}{*}{ TEC $\left.\left(10^{6} / \mu 1\right)\right)$} & Positive $(n=44)$ & $03.77 \pm 0.17$ & $03.43-04.17$ & 0.59 \\
\hline & $\operatorname{Negative}(n=96)$ & $03.65 \pm 0.13$ & $03.40-03.90$ & \\
\hline \multirow[t]{2}{*}{$\operatorname{TLC}\left(10^{3} / \mu 1\right)$} & Positive $(n=44)$ & $06.43 \pm 0.33$ & 05.77-07.09 & 0.49 \\
\hline & $\operatorname{Negative}(n=96)$ & $06.69 \pm 0.20$ & 06.29-07.09 & \\
\hline \multirow[t]{2}{*}{$\operatorname{PCV}(\%)$} & Positive $(n=44)$ & $29.57 \pm 0.58$ & $28.39-30.75$ & 0.03 \\
\hline & Negative $(n=96)$ & $28 \pm 0.40$ & $27.20-28.80$ & \\
\hline \multirow{2}{*}{$\operatorname{ESR}\left(\mathrm{mm}\right.$ in $1^{\mathrm{st}} \mathrm{hr}$.) } & Positive $(n=44)$ & $0.74 \pm 0.10$ & $0.53-0.95$ & 0.42 \\
\hline & Negative $(n=96)$ & $0.65 \pm 0.06$ & $0.52-0.77$ & \\
\hline \multirow[t]{2}{*}{$\mathrm{Hb}(\mathrm{g} / \mathrm{dl})$} & Positive $(n=44)$ & $08.75 \pm 0.16$ & 08.43-09.08 & 0.56 \\
\hline & Negative $(n=96)$ & $08.87 \pm 0.11$ & 08.66-09.08 & \\
\hline \multirow[t]{2}{*}{ Lymphocyte (\%) } & Positive $(n=44)$ & $58.77 \pm 1.00$ & $56.75-60.79$ & 0.99 \\
\hline & Negative $(n=94)$ & $58.79 \pm 0.95$ & $56.90-60.68$ & \\
\hline \multirow[t]{2}{*}{ Neutrophil (\%) } & Positive $(n=44)$ & $32.18 \pm 0.93$ & $30.31-34.05$ & 0.87 \\
\hline & Negative $(n=94)$ & $32.43 \pm 0.91$ & $30.62-34.23$ & \\
\hline \multirow[t]{2}{*}{ Monocyte (\%) } & Positive $(n=44)$ & $04.05 \pm 0.30$ & $03.44-04.65$ & 0.54 \\
\hline & Negative $(n=94)$ & $04.30 \pm 0.24$ & $03.82-04.77$ & \\
\hline \multirow{2}{*}{ Eosinophil (\%) } & Positive $(n=44)$ & $04.70 \pm 0.37$ & $03.95-05.46$ & 0.64 \\
\hline & Negative $(n=94)$ & $04.52 \pm 0.20$ & $04.11-04.93$ & \\
\hline \multirow[t]{2}{*}{ Basophil (\%) } & Positive $(n=44)$ & $0.39 \pm 0.08$ & $0.22-0.55$ & 0.01 \\
\hline & Negative(n=94) & $0.17 \pm 0.04$ & $0.09-0.25$ & \\
\hline
\end{tabular}

The effects of $M$. bovis infections on hematological parameters were measured on both CFTT reactor cattle and CITT reactor cattle. In case of CITT reactor cattle, targeted samples were 49. From these 49 CITT reactor cattle, 44 good quality blood samples were got and five CITT positive cattle were missed due to farmer's noncooperation, selling of animals etc. Ninety-six CFTT negative cattle were used as control groups. Same hematological parameters were used for the CITT infected cattle, the PCV values were significantly $(\mathrm{P} \leq 0.05)$ higher than the control groups. The values of $\mathrm{Hb}(8.75 \pm 0.16 \mathrm{gm} / \mathrm{dl})$ and TEC of infected cattle were slightly lower $(\mathrm{P}=0.56)$ and higher $(\mathrm{P}=0.59)$ respectively than the healthy ones. The ESR values were also insignificantly $(\mathrm{P}=0.42)$ higher in tuberculin reactors than the tuberculin non-reactors. In case of White Blood Cells (WBC), both total concentrations per cubic mm of blood and percentage of individual white cells members were detected in both infected and non-infected groups. Leukocyte concentrations per cubic $\mathrm{mm}$ of fresh blood were insignificantly $(\mathrm{P}=0.49)$ lower than control groups. Among the different members of Leukocyte groups, only the values of Basophils were significantly higher $(\mathrm{P}=0.01)$ in infected groups in comparison with control groups. The other 4 members showed insignificant difference between CITT positive and negative cattle. Among these four members, only the values of Eosinophil were higher and the values of Lymphocytes, Neutrophils and Monocytes were lower in infected group of cattle than the negative group of cattle.

Table 3. Comparison of serum biochemical parameters between tuberculin reactor and non-reactor cattle with Mycobacterium bovis infection.

\begin{tabular}{lllll}
\hline Variable & Category & Mean \pm SEM & $95 \%$ CI & P-value \\
\hline Total protein $(\mathrm{g} / \mathrm{dl})$ & Positive $(\mathrm{n}=45)$ & $08.84 \pm 0.20$ & $08.44-09.24$ & 0.30 \\
& Negative $(\mathrm{n}=55)$ & $09.13 \pm 0.19$ & $08.76-09.50$ & \\
Calcium $(\mathrm{mg} / \mathrm{dl})$ & Positive $(\mathrm{n}=45)$ & $09.85 \pm 0.24$ & $09.36-10.34$ & 0.16 \\
& Negative $(\mathrm{n}=55)$ & $09.27 \pm 0.32$ & $08.63-9.90$ & \\
Phosphorus $(\mathrm{mg} / \mathrm{dl})$ & Positive $(\mathrm{n}=45)$ & $08.63 \pm 0.30$ & $08.02-09.24$ & 0.24 \\
& Negative $(\mathrm{n}=55)$ & $08.15 \pm 0.27$ & $07.62-08.69$ & \\
Creatinine $(\mathrm{mg} / \mathrm{dl})$ & Positive $(\mathrm{n}=45)$ & $01.71 \pm 0.05$ & $01.61-01.81$ & 0.64 \\
& Negative $(\mathrm{n}=55)$ & $01.75 \pm 0.05$ & $01.64-01.85$ & \\
SGOT (IU/L) & Positive $(\mathrm{n}=39)$ & $59.43 \pm 2.32$ & $54.74-64.12$ & 0.23 \\
& Negative $(\mathrm{n}=51)$ & $63.68 \pm 2.49$ & $58.67-68.69$ & \\
\hline
\end{tabular}

The values for biochemical tests are shown in Table - 03. Within 93 CITT done animals, 49 animals showed CITT positive result. Among 49 CITT positive animals, 45 good quality of serum samples were got for biochemical analysis. The 55 control serum samples were also taken from respected CITT positive farms considering the different 


\section{Hossain and others}

demographic characteristics like lactation status, Body Condition Score (BCS), parity, milk production, body weight etc. The results indicated that there was no significant difference in the total protein contents between the tuberculin reactors and tuberculin non-reactors. The two major blood trace elements, the Calcium and Phosphorus level showed higher values in TB positive animals than TB negative animals but these higher values were statistically insignificant. The important liver enzyme, SGOT values and important nitrogenous compound, Creatinine values were insignificantly higher in control group of animals than the positive group of animals.

\section{DISCUSSION}

The comparison of hematological parameters between bTB-infected and bTB- noninfected dairy cattle was a first time effort in intensive dairy farms with high yielding cross breeds at the eastern part of Bangladesh. This study first demonstrated the comparison of different hematological parameters of bTB suspected (CFTT positive) dairy cattle with control groups and then with more follow - up test (CITT) positive dairy cattle with control groups. In both cases, the values of PCV percentage were significantly $(\mathrm{P} \leq 0.05)$ and the values of TEC were insignificantly higher in positive groups than the controls. But some earlier studies found significant decreased values of PCV and TEC in tuberculin reactor cattle (Salman et al., 2013; Javed et al., 2010; Samad and Rahman, 1986; Shettar et al., 2011). The causes of this opposite results are uncertain. Previous studies on human patients agreed that the mean of the total WBC count in pulmonary TB patients is usually normal or not significantly elevated as compared to the normal mean of a population (Akpan et al., 2012; Shareef and Amin, 2012). In this study, both the TLC values were slightly higher in CFTT reactors and slightly lower in CITT reactors. Both are statistically insignificant. Slightly higher TLC values (statistically insignificant, $\mathrm{P} \leq 0.05$ ) in tuberculin reactor dairy cattle were also reported by Shettar et al., 2011. On the other hand, slightly lower (statistically insignificant) TLC values in tuberculin reactor dairy cattle were also reported by Javed et al., 2010. In differential Leukocyte percentage, only Basophil showed significant higher values $(\mathrm{P} \leq 0.05)$ both in primary screening CFTT reactor and more definite CITT reactor cattle. It might be due to allergies or parasitic infection.

Both in tuberculin positive and negative reactors, the values of organic macromolecular compound total proteins were within normal ranges (6.4-9.5gm/dl) (http://www.infovets.com/books/dairy/D/D080.htm). But in tuberculin positive reactor cattle, the values were slightly lower than negative reactor cattle and these variations were statistically insignificant $(\mathrm{P}=0.30)$. In some earlier studies done on cattle and European wild boars, the insignificant variations were reported between tuberculin reactors and tuberculin nonreactors (Javed et al., 2010; Shettar et al., 2011; Vidal et al., 2006). Higher total protein values but statistically insignificant $(\mathrm{P}=0.065)$ were also reported in healthy controls than patients with active tuberculosis (Zargar et al., 2001). In this study, the Creatinine values between CITT positive cattle and control groups showed insignificant variations and the values were slightly higher than physiological values $(0.9-1.7 \mathrm{mg} / \mathrm{dl})$. These higher values may be due to decrease fluid volume that is hemoconcentration or dehydration, high protein diet or recent meal.

In this study, the serum SGOT level is within normal ranges (40-130 IU/L) both in CITT positive and negative reactors. SGOT is one of the important enzymes in liver and will be increased when liver cells are damaged. The liver is also one of the organs for extrapulmonary TB (Hickey et al., 2015). In this study, the liver of CITT reactor cattle might be unaffected from TB lesions. Interestingly, statistically significant $(\mathrm{P} \leq 0.05)$ increase level of serum SGOT in TB reactor cattle from TB non-reactor cattle were documented from an earlier study (Shettar et al., 2011) and fortunately insignificant $(\mathrm{P}=0.614)$ variations of transaminases were also reported between human patients with $\mathrm{TB}$ positive and healthy controls (Zargar et al., 2001).

The study demonstrated the difference in blood parameters between bTB affected and apparently healthy cattle. The values for TEC, $\mathrm{Hb}$ and PCV were higher in infected group in compare to the negative or control group (based on CFTT) and the PCV values were significantly higher. In case of samples of bTB confirmed by CITT, the PCV values were significantly higher in infected groups than control groups. Among the different members of leukocyte groups (in both CFTT \& CITT) only the values of Basophils were significantly higher in infected groups. In case of serum biochemical profile, there were no significant variations of Total Protein (TP), Albumin, Calcium; Phosphorus, Creatinine and SGOT levels between CITT reactors and non-reactors. Future researches with larger sample size are recommended.

\section{ACKNOWLEDGEMENTS}

The author would like to acknowledge the University Grants Commission of Bangladesh (HEQEP Project, CP: 2180) for funding the research and Department of Physiology, Pharmacology and Biochemistry, Chittagong Veterinary and Animal Sciences University for providing technical support to conduct the study.

\section{REFERENCES}

1. Akpan PA, Akpotuzor JO and Akwiwu C (2012). Some haematological parameters of tuberculosis (TB) infected Africans: the Nigerian perspective. Journal of Natural Science Research 2: 50-57.

2. Ashford DA, Whitney E, Raghunathan P and Cosivi O (2001). Epidemiology of selected mycobacteria that infect humans and other animals. Scientific and Technical Review, Office of International des Epizooties 20:325-337.

3. Bari MS, Rana EA, Ahaduzzaman M, Masud AA, Das T and Hasan T (2018). Hemato-biochemical parameters of Pestedes Petits Ruminants (PPR) affected goats in Chittagong, Bangladesh. Journal of Advanced Veterinary and Animal Research 5:211-217. 
4. Haque MM, Belton B, Alam MM, Ahmed AG and Alam MR (2016). Reuse of fish pond sediments as fertilizer for fodder grass production in Bangladesh: Potential for sustainable intensification and improved nutrition. Agricultural Ecosystem and Environment 216:226-236.

5. Hickey AJ, Gounder L, Moosa MYS and Drain PK (2015). A systematic review of hepatic tuberculosis with considerations in human immunodeficiency virus co-infection. BMC Infectious Diseases 15:209.

6. Jain NC (1986). Schalm's Veterinary hematology, $4^{\text {th }}$ edition, Lea and Febiger Philadelphia. pp:1.

7. Javed MT, Ahmad L, Irfan M, Ali I, Khan A, Wasiq M, Farooqi FA, Latif MS and Cagiola M (2010). Hematological and serum protein values in tuberculin reactor and non- reactor water buffaloes, cattle, sheep and goats. Pakistan Veterinary Journal 30:100-104.

8. Javed MT, Usman M, Irfan M, Cagiola M (2006). A study on tuberculosis in buffaloes: some epidemiological aspects, along with haematological and serum protein changes. Veterinarski Arhieve 76:193-206.

9. Ježek J, Klopčič M and Klinkon M (2006) Influence of age on biochemical parameters in calves. Bulletin of the Veterinary Institute in Pulawy 50:211-214.

10. Priya JM, Rajashekar M and Sumanlatha G (2015). Role of Immuno-Endocrine Interactions in Tuberculosis. Donnish Journal of Infectious Diseases and Immunity 1:1-9.

11. Salman SS, Al-Hadithy HA and Mahmood MM (2013). The Hematological Parameters and Serum Protein Values in Tuberculin Reactor and Non-reactor Dairy Cattle. Al-Anbar Journal of Veterinary Science 6:124-130.

12. Samad MA and Rahman MS (1986). The incidence of bovine tuberculosis and its effect on certain blood indices in dairy cattle of Bangladesh. Indian Journal of Dairy Science 39:231-234.

13. Shaikat AH, Hassan MM, Khan SA, Islam MN, Hoque MA, Bari MS and Hossain ME (2013). Hemato-biochemical profiles of indigenous goats (Capra hircus) at Chittagong, Bangladesh. Veterinary World 6:789-793.

14. Shareef HA and Amin NRM (2012). Abnormalties of hematological parameters in newly diagnosed pulmonary tuberculosis patients in Kirkuk City. Journal of Babylon University/ Pure and Applied Sciences 20:1486-1492.

15. Sharma IJ and Singh HS (2000). Students Laboratory Manual of Veterinary Physiology. ${ }^{\text {st }}$ edition, Kalyani Publishers, Ludhiana, New Delhi, India. pp: 7.

16. Shettar M, Nalini TS, Kumar KRA, Ravikumar P and Azeemulla HR (2011). Hematological and biochemical studies in tuberculin test positive reactors. International Journal of Pharma and Bio Sciences 2:16-22.

17. Tsegaye W, Aseffa A, Mache A, Mengistu Y, Berg S and Ameni G (2010). Conventional and molecular epidemiology of bovine tuberculosis in dairy farms in Addis Ababa city, the capital of Ethiopia. International Journal Applied Research Veterinary Medicine 8:143-151.

18. Uddin ASMT, Akter MR, Khatun MN, Mannan MA, Rahman MM and Kabir SML (2014). Investigation of bovine tuberculosis in Rangpur division of Bangladesh. Journal of Life Science Research 1:1-4.

19. Vidal D, Naranjo V, Mateo R, Gortazar C and de la Fuente J (2006). Analysis of serum biochemical parameters in relation to Mycobacterium bovis infection of European wild boars (Sus scrofa) in Spain. European Journal of Wildlife Research 52:301-304.

20. Zargar AH, Sofi FA, Akhtar MA, Salahuddin M, Masoodi SR and Laway BA (2001). Adrenocortical reserve in patients with active tuberculosis. The Journal of the Pakistan Medical Association 51:427-433 